\title{
Validity of Context-Specific versus Broad Individual Differences in International Assignments
}

\section{Validez de las Diferencias Individuales Amplias frente a Especificas del Contexto}

\author{
Julio E. Fernández Cueto and Juan I. Sánchez \\ Florida International University
}

\begin{abstract}
Previous research in expatriate selection has employed broad-based personality factors to test the value of personality variables as predictors of performance during international assignments. In contrast, this study focused on developing and testing the incremental validity of context-specific competencies. Drawing from the literature on expatriate management, a measure named the Global Competency Self-Assessment was created involving context-specific competencies deemed important for international assignments. Using hierarchical regression, results from fifty-seven expatriates in the Dominican Republic showed that these context-specific competencies predicted performance above and beyond the broadbased Big Five personality factors.

Keywords: Big Five, personality, validity, context-specific, broad competencies.

Resumen. La investigación previa sobre la selección de expatriados ha empleado factores de personalidad amplios para probar el valor de las variables de personalidad como predictors del desempeño en las asignaciones internacionales. En contraste, este studio se centra en el desarrollo y comprobación de la validez añadida de competencias específicas del contexto. A partir de la literatura sobre gestión de expatriados, una medida denominada Auto-evaluación de la Competencia Global fue creada, envolviendo competencias específicas del contexto que parecían importantes para las asignaciones internacionales. Usando regresion jerárquica, los resultados de 57 expatriados en la Repúbica Dominicana mostraron que estas competencias específicas del contexto predecían el desempeño más allá de los factores de personalidad amplios basados en los Big Five.

Palabras clave: Big Five, personalidad, validez, específico del context, competencias amplias.
\end{abstract}

As companies compete across global markets, their effectiveness depends partly on the level of competence that their executives possess in international endeavors such as joint ventures, foreign subsidiaries, and emerging markets (Caligiuri, 2000). One of the most widely used means of developing global competence is through the use of international assignments (IA) (Aycan, 2001; Gregersen, Morrison, \& Black, 1998; Oddou, Gregersen, Black, \& Derr, 2001). Having valid means of identifying those who are likely to succeed on IAs has therefore become critical for multinational companies.

Researchers argue that success overseas depends at least in part on individual differences such as personality traits, individual skills, or competencies (Arthur \& Bennett, 1995; Black, Mendenhall, \& Oddou, 1991; McCall, 1994; Spreitzer, McCall, \& Mahoney, 1997). There is evidence supporting the use of personality variables in the prediction of job performance (Barrick \& Mount, 1991; Hough, Eaton, Dunnette, Kamp, \&

Correspondence on this article should be sent to Juan I. Sanchez, Department of Management and International Business, College of Business Administration, Florida International University, 11200 SW8 Street, Miami, FL 33199, USA. E-mail: sanchezj@fiu.edu
McCloy, 1990). Recent studies such as Caligiuri (2000) and Dalton and Wilson's (2000) have begun to systematically assess the extent to which these findings regarding the validity of personality factors generalize to performance on IA. These studies, however, adopted a broad perspective for assessing personality, namely the Big Five Factors (i.e., extraversion, conscientiousness, agreeableness, emotional stability, and openness to experience or intellect; Digman, 1990; McCrae and Costa, 1987).

A possible limitation of these studies is that broad predictors (i.e. Big Five Factors) do not specifically take into account the particular context of international assignments. Without question, IAs are unique in and of themselves, posing numerous challenges that are not necessarily encountered at the domestic level, or at least not encountered in the same magnitude. For instance, aside from fulfilling regular job duties, individuals in IAs need to adjust to a new surrounding, a new culture, unfamiliar rules and regulations, and often even to a new language. Moreover, IAs may involve moving a whole family to a new country or separating family members from each other, all of which can be stressful (Sanchez, Spector, \& Cooper, 2000). To better understand what individual differ- 
ences explain performance overseas, predictors should be specific to the challenges faced during international assignments. If the context of IAs makes them unique, predictors that take into account this context will not only help in selecting potential candidates, but also enhance our theoretical understanding of the factors that lead to successful IAs.

In summary, the study described herein aims at identifying context-specific competencies which have been identified in the literature as potentially valuable to succeed on IAs. Additionally, this study will test if these context-specific competencies provide incremental validity in predicting performance during IAs above and beyond broader factors like the Big Five. To shed light on the specific context of IAs, the next section reviews the literature on the selection of international assignees.

\section{Selecting for International Assignments}

The term international executive has been defined as an executive holding a job with some international scope, either in an IA or on a job dealing with international issues (Spreitzer et al., 1997). Research has shown that, for the past three decades, the primary criterion used in selecting an individual for an IA has been his or her technical skill in a domestic context (Black, Gregersen, Mendenhall, \& Stroh, 1999; Earley, 1987; Marquardt \& Engel, 1993; Mendenhall, 2001). However, this approach appears to be shortsighted. Some of the traits, attributes, and management styles that lead to success in a domestic context might lead to poor performance across different cultures (Mendenhall, 2001). For instance, without cross-cultural skills, individuals might not have the opportunity to apply their technical expertise. In fact, premature expatriate returns are often attributed to firms rapidly selecting technically qualified candidates who lack the crosscultural communication or adjustment skills needed to succeed abroad (Black, Gregersen, et al., 1999; Sanchez, Spector, \& Cooper, 2000).

Although organizations are still using technical competence as their primary selection predictor, the relationship between personality and performance during IAs has not been ignored. However, conjectures regarding the role of personality in IA were primarily based on anecdotal evidence, intuition, face validity, or interviews, resulting in a body of literature that is probably inadequate to answer critical questions concerning the contribution of personality to successful IAs (see Deller, 1997, for a critical evaluation of the research in expatriate selection). More recently, researchers have begun to assess empirically the value of personality variables to predict success on IA. Specifically, empirical studies testing the validity of the Big Five Factors in the expatriate selection literature are discussed in the next section.

\section{Big Five in Expatriate Selection}

The Five Factors derive from a lexical tradition that attempts to identify the structure of personality traits by analyzing the adjectives that people use to describe themselves and others (Dalton \& Wilson, 2000). The factors are emotional stability (tendency to experience negative affect such as fear, sadness, anger, guilt), extraversion (general tendency towards sociability, assertiveness, being talkative), openness to experience (describing those willing to entertain novel ideas and unconventional values), agreeableness (describing traits such as sympathy, cooperativeness, helpfulness towards others), and conscientiousness (a general tendency towards achievement, order, dutifulness, selfdiscipline) (Dalton \& Wilson, 2000).

Ones and Viswesvaran (1997) first made a case for the use of the Big Five Factors in expatriate selection. Drawing from the domestic literature on personnel selection, they developed a series of propositions regarding the utility of the Big Five in the prediction of several expatriate criteria, including job performance. Subsequent studies of the Five Factor Model have found support for the use of personality in selection for overseas assignments. First, Caligiuri (2000) found that the Five Factors as a group significantly predicted two criteria, namely desire to terminate the assignment early $\left(\operatorname{adj} . \mathrm{R}^{2}=.11, \mathrm{p}<.01\right)$, and supervisor-rated performance $\left(\operatorname{adj} . \mathrm{R}^{2}=.09, \mathrm{p}<.05\right)$. Additionally, Caligiuri found conscientiousness to be significantly correlated with supervisor-rated performance $(\mathrm{r}=.35, \mathrm{p}<.01)$. In a different study of expatriates, Dalton and Wilson (2000) found a positive relationship between job performance and two of the Big Five Factors, namely conscientiousness $(\mathrm{r}=.47, \mathrm{p}<.05)$ and agreeableness $(\mathrm{r}=.49, \mathrm{p}<.05)$.

The magnitude of these correlations still suggests modest effect sizes for most of these broadly defined personality traits. The role of individual differences in predicting overseas job performance may need to be painted with thinner brushes than those provided by the Big Five Factors. To better comprehend the relationship between individual differences and success on IA, such individual characteristics must be defined in the proper context. This argument has been debated in the bandwidth-fidelity dilemma. For instance, Ones and Viswesvaran (1996) argued that broader traits are better predictors because they have greater reliability than narrower traits, and the variance in job performance associated with broad factors generalizes across situations. On the contrary, Ashton (1998) argues that too much information is lost using broad factors, inhibiting a better understanding of which narrower facets have the strongest relationship with any criteria of interest. Schneider, Hough, and Dunnette (1996) maintained that using narrower traits enhances our understanding of work behavior because such traits retain specificity that can add substantially to criterion- 
related validity (see Ashton, 1998; Hogan \& Roberts, 1996; Ones \& Viswesvaran, 1996; Schneider, et al., 1996 for differing views of the bandwidth-fidelity dilemma).

In a way, the study described herein represents an extension of the bandwidth-fidelity dilemma to the arena of IA. Specifically, we focused on whether context-specific competencies thought to be particularly important for IAs are better predictors of performance than general, context-unspecific characteristics. A review of some of the specific competencies identified as possibly being predictive of success during IAs follows.

\section{Global Competencies}

Cultural sensitivity. Although referred to with different names, some form of cross-cultural sensitivity is often mentioned as a key trait of successful international executives. The literature is filled with stories and anecdotes of overseas managers who, unaware of cultural differences when dealing with locals, they either jeopardized or spoiled a business deal. Goldsmith and Walt (2000) conducted interviews with over 200 current leaders and potential leaders across the globe and concluded that respect for differences in people is one of the most important qualities of a successful international executive. Additionally, expatriates who are non-judgmental when interpreting behaviors of host country nationals are more successful in IAs than those who are judgmental (Hogan \& Goodson, 1990; Marquardt \& Engel, 1993; Mendenhall \& Oddou, 1985; Stahl, 2001).

Other factors related to cultural sensitivity that are mentioned in the literature include respect or understanding of diverse viewpoints (Gregersen et al., 1998; Black \& Gregersen, 1999) and empathy (Marquardt \& Engel, 1993). Cultural Sensitivity is thus defined here as being aware of differences when working with people from cultures other than one's own, while being non-judgmental about these differences; being capable of seeing one's original culture through the eyes of others; and listening and going the extra mile to understand the perspectives of people from other cultures.

Adaptability/Flexibility. Arthur and Bennett (1995) found that one of the top factors perceived to contribute to the success on IAs was adaptability/flexibility. Early returns from assignments often occur because of adjustment problems (Church, 1982). Indeed, due to the unpredictable nature of global markets, some form of adaptability/ flexibility would seem important for anyone in an IA. In other words, as the context changes, the behaviors must change accordingly. This pattern is magnified in an international context, in which creative leadership in the midst of uncertainty is not an option, but rather a norm (Black,
Morrison, \& Gregersen, 1999). Moreover, because of uncertainty, a significant level of risk taking is required from the international executive. During IAs, the individual must be willing to bend some rules even if it means going against headquarters (Lipp \& Clarke, 2000). Adaptability/ Flexibility also becomes important when communicating or negotiating across cultures. The potential for conflict during negotiations with foreigners is perhaps greater than in negotiations at a domestic level, so collaborative negotiation styles are imperative as they help individuals focus on understanding other parties and cultures, instead of forcing others to see situations in a certain manner (Black, Gregersen, et al., 1999).

Elements mentioned in the literature related to adaptability/flexibility include seeking feedback to make sense of the work environment (McCall, 1994), ability to communicate (Black, Gregersen, et al., 1999), managing uncertainty (Aycan, 2001; Gregersen et al., 1998), and tolerance for ambiguity (Stahl, 2001; Odenwald, 1996). Adaptability/flexibility is defined here as adjusting to an unpredictable and ambiguous environment by considering diverse ideas and seeking feedback and, as result, taking calculated risks to modify one's behavior accordingly; being open-minded, willing to compromise and engage in give-and-take; knowing when not to indoctrinate others on the "right" way of doing things; and not investing oneself in just one course of action.

Global vision. In today's global markets, leaders need to see the world with a greatly expanded field of vision and values, understanding not only the economic implications of globalization, but also its cultural, legal, and political ramifications (Goldsmith \& Walt, 2000). Leaders need to identify worldwide business opportunities to learn sources of competitive advantage, political situations, and country-specific conditions that might benefit their organizations. Although allowing time for research, they should not allow the search for clarity to jeopardize first mover advantages through "paralysis-by-analysis;" they should quickly separate the figure from the background, not waiting for the entire picture to come into focus before moving ahead (Gregersen, et al., 1998). For instance, international executives should recognize global market opportunities, scouting the environment for the most cost-effective quality inputs of production that confer enormous market advantages to their companies (Black, Morrison, et al., 1999).

Being aware of possible strategic advantages, however, is not enough. To take advantage of these opportunities, individuals in IAs will need the ability to motivate people from different cultures, because strategies that are effective in one culture might not be necessarily effective in a different one (Goldsmith \& Walt, 2000). Moreover, regardless of how much knowledge and vision a person has, s/he still needs to rely on locals for implementation. For this reason, an 
expatriate manager must have the ability to share his/her vision in a convincing manner with people from diverse cultures.

Other elements mentioned in the literature that are related to global vision include ability to gain consensus (Odenwald, 1996), knowing how issues impact each other across countries (Saner, Yiu, \& Sondergaard, 2000), ability to develop and convey a shared vision (Marquardt \& Berger, 2000), and recognizing and connecting global market trends (Marquardt \& Berger, 2000). Global vision is thus defined here as the "ability to connect the dots" among economic, legal, social, and cultural issues across diverse countries; ability to see the whole picture and how issues impact each other; being imaginative and capable of providing a global vision that captures the imagination of others; and identifying the most critical or central aspects of an issue and being able to connect them.

Global Citizenship. Companies having successful expatriate assignments place a candidate's openness to new cultures on the same level of importance as the person's technical know-how (Black \& Gregersen, 1999). In fact, expatriates who complete IAs are often those who willingly experiment with different customs, establishing social ties to the local residents (Black \& Gregersen, 1999). Furthermore, this willingness to be in touch with host country nationals has been found to facilitate cross-cultural adjustment in expatriates (Gregersen, et al., 1998). Adjustment, however, entails neither a complete nor a permanent personal transformation, nor agreeing with all of the foreign cultures' ideas, principles and behaviors. Rather, it implies expressing admiration and respect for the local culture without rejecting one's own native culture. Instead of absorbing oneself in an internal conflict regarding two possibly contradictory cultures competing for the same space, the executive should identify with both the host and parent culture, thereby realizing that a multicultural identity is indeed feasible (Sanchez, et al., 2000). Actually, the most respected expatriates in an international business community are bicultural, speak the local language, and are well integrated into both the local culture and the community of expatriates (Black, Gregersen, et al., 1999).

Another requisite for individuals to succeed in IAs is developing and maintaining long-standing relationships across nationalities. The expatriate literature suggests that having an interest in developing these relationships helps expatriates develop solid ties with host nationals, who in turn provide critical work information as well as feedback regarding the manager's performance (Black, Gregersen, et al., 1999). Related aspects include warmth in human relations (Marquardt \& Engel, 1993), sociability and interest in other people (Stahl, 2001), need to establish relationships (Hitt, Keats, \& DeMarie, 1998), building partnerships (Goldsmith \& Walt, 2000), and interest in different cultures (Odenwald, 1996). Being a global citizen is thus defined here as liking to establish relationships with and a sense of belonging to different cultures and nations; enjoying the challenge of working in cultures different than ones' own; and having an ability to identify with multiple cultures without feeling that cultural loyalties are mutually exclusive.

Resiliency/Hardiness. Being resilient is probably helpful in all types of jobs. However, the high degree of uncertainty that one faces when working across cultures increases the importance of resilience during IAs. Inability to cope with stress during IAs would probably elicit both personal and professional withdrawal behaviors such as depression, absenteeism, and turnover, which in turn result in poor performance or even assignment termination (Caligiuri, 2000). Resiliency is also important for IAs because not only are the stressors new and unfamiliar, but coping responses that worked at home may not work abroad, thereby creating additional stress (Sanchez et al., 2000). One such way to cope is by developing what Mendenhall and Oddou (1985) called stability zones. These zones include activities that allow for the temporary withdrawal from stressful situations in order to gain a different view of the new culture. Thus, having varied interests and enjoying multiple activities might help create stability zones for the individual, which in turn can help with coping. Another reason why resiliency and hardiness are essential for succeeding in IAs lies in the criticism that people encounter when working across different cultures. Spreitzer et al. (1997) suggested that it is through criticism that executives learn from their past experiences. Certainly, when working across cultures one's own mistakes are known often through the feedback from local managers, so it seems that the ability to listen and accept criticism is of heightened importance.

Other elements mentioned found in the literature that are related to resiliency/hardiness include the ability to cope with uncertainty and conflict (Aycan, 2001) and having a sense of humor (Marquardt \& Engel, 1993; Odenwald, 1996). In summary, resiliency/hardiness is defined here as not breaking in the face of stress, criticism, and frustration; finding gratification in multiple activities; using humor when dealing with difficult situations; not getting frustrated by sudden changes, and being ready to switch focus and deal with them; and understanding that there are transition periods and that things do not happen overnight.

Global competitor. Technology and globalization have increased the speed with which the global marketplace operates. We have already argued that, in today's fast-paced competitive environment, too much planning can be detrimental. Consequently, individuals need to understand markets quickly and to act before their competitors do. But to make the first move, one must also understand competitive conditions (Gregersen et al., 1998). Individuals in international 
assignments must develop a good knowledge of their industry at a global level, not only becoming familiar with company assets, subsidiaries, and business partners, but also monitoring and understanding their competition. Acquiring this mindset requires at least two things, a persistent desire to learn and technological know-how. Given today's rapid speed of business, missing possible key relationships, important facts, or market opportunities can be costly.

Other elements mentioned in the literature that are related to global competitiveness include effective use of technology (Hitt et al., 1998), technological savvy (Goldsmith \& Walt, 2000), and an understanding of strategic capabilities and intent of competitors (Black, Morrison, et al., 1999). In essence, being a global competitor is defined here as understanding the nature of global markets operating at the speed of electronic commerce; monitoring competition and being able to stay ahead; understanding that the race for survivorship starts fresh everyday; being capable of taking quantum leaps that leave the competition behind; and adjusting to and taking advantage of technology.

\section{Summary and Hypotheses}

As companies move outside of their borders and into global markets, their success depends on the availability of executives with international talent. Drawing from the context of IAs, several competen- cies were identified as being important for international executives. These "Global Competencies" are cultural sensitivity, adaptability/ flexibility, global vision, global citizenship, resiliency/hardiness, and global competitor (see Table 1 for specific examples of how Global Competencies take into account the context of IA). One way to demonstrate the valueadded by these competencies is to test their criterionrelated validity by establishing a relationship between them and a criterion of performance. Hence, we hypothesized that

\section{H1: Global competencies will be positively correlat-} ed with supervisory performance ratings.

Prior studies have explored the use of personality characteristics as possible predictors of overseas success. These studies, however, relied on broad-based characteristics that are not specific to the uniqueness of IAs. There are challenges faced by international executives and expatriates that require specific manifestations and combinations of general personality traits not generally needed for other jobs. Thus, it is quite possible that the prior reliance on broad predictors has limited our understanding of the role individual differences play during IAs. Therefore,

H2: Global competencies will predict supervisory performance ratings above and beyond the Big Five personality factors.

Table 1. Examples of how Global Competencies Take into Account the Context of International Assignments

$\begin{array}{lll}\text { Global Characteristic Context } & \begin{array}{l}\text { Example of Global Characteristic taking into account } \\ \text { context of IA }\end{array}\end{array}$
context of IA

Cultural Sensitivity During IA people must often work with and among individuals of different cultures.
Being non-judgmental when interpreting behaviors of others; understanding different viewpoints helps avoid blunders due to cultural ignorance.

Being open-minded; engaging in give and take compromise can help avoid some conflict.
Establishing social relationships across cultures allows access to insight and knowledge provided only by locals, perhaps vital information necessary to succeed. ly in a different culture, using a different language, and under different laws and customs, making them more dependent on others for guidance.
Global Citizenship

Resiliency/Hardiness
During IA not only are stressors new and unfamiliar, but coping responses that worked at home might fail or be unavailable causing additional stress.
Not breaking in the face of stress allows individuals to better cope and adjust during IA; finding gratification in multiple activities allows temporary withdrawal from stressful situations which might help with coping.
Global Competitor
When working in new markets during IA, individuals need to learn and understand the new market quickly in order to act before their competitors do to gain firstmover advantages.
Having a persistent desire to learn will enable individuals to keep up with the rapid pace of today's international markets, and not miss important facts or market opportunities. 


\section{Method}

\section{Scale Development}

Item generation. The first step was to create a list of items to assess the content domains of the global competencies previously defined. The authors generated approximately 150 items reflecting these competencies. These items involved a single sentence written in plain English (e.g., "most problems have one best solution to resolving them"). Then, a multi-step process described below was used to establish whether these items were content-valid.

First, an initial content validation check was conducted by having a panel review the items. Twelve doctoral students in industrial and organizational psychology were asked to identify the characteristic that each item best reflected. The students were told they could assign the items to as many competencies as they deemed appropriate. Because the goal was to identify one-dimensional items capable of providing a simple factorial structure, items that tapped several competencies at once were eliminated. The elimination criteria were that at least four of the six raters needed to agree regarding the competency to which the item was relevant, while no more than two raters agreed on the same item belonging to a second competence. This process resulted in 54 items kept for further item analysis. Using a Likert scale ranging from strongly disagree (1) to strongly agree (5) 1, a survey named the "Global Competencies Self-Assessment" was created. The next step involved a factor analysis to determine the factor structure of this instrument.

Pilot Study for Scale Creation and Refinement. The Global Competencies Self-Assessment was administered to a group of 311 culturally diverse, graduate and undergraduate students at a primarily commuter state university serving an urban area heavily populated by Hispanics and other minorities. This sample seemed adequate for a pilot study because these individuals had exposure to diverse cultures.

Of the 311 participants, $69 \%$ were female and $31 \%$ were male, $15 \%$ were graduate students and $85 \%$ were undergraduates. Additionally, $23 \%$ of the students came from business classes while $77 \%$ came from psychology classes. Regarding employment status, $64 \%$ of the participants reported working at least part time. Although the majority of the sample was Hispanic $(68 \%)$, most of the participants $(80 \%)$ reported having lived mostly or exclusively in the U.S. their entire lives. About 75\% reported both of their parents being born outside of the continental U.S

Principal components analysis with an oblique rotation was conducted to determine the number of dimensions underlying the 54 items. Although the factor analysis was performed with the expectation that six factors were present in the measure, an exploratory factor analysis was preferred over a con- firmatory one because (1) the six competencies defined earlier were thought to be context-activated, composite manifestations of an undetermined number of underlying traits and (2) we were more interested in a psychometrically-sound and practical measure than in testing a theory of competencies. For this same reason (i.e., competencies were assumed to be complex and inter-correlated), an oblique rotation was employed.

Because items from the adaptability/flexibility scale loaded on multiple factors thus lacking perfect, simple structure, the screeplot of eigenvalues was inspected. Five and seven-factor solutions were suggested by the screeplot. The seven-factor solution was not interpretable: items with loadings on at least one of the factors did not seem to make sense when considered together, and a second factor was made up of only two items. In contrast, the five-factor solution was interpretable, even though five items had to be deleted due to double-loadings.

Overall the results of the factor analysis supported this five-factor solution, with 41 items loading primarily on just one of the factors by a factor loading of at least .40, and two items loading at least .35 but having small loadings on all other factors. Moreover, of these 43 items clearly loading on only one factor, 31 (72\%) loaded consistently with the previously carried out content validity assessment. The 12 items that did not load consistently with the content validity analysis, were kept because they made substantive sense when considered together with the other items in the same scale. The final step was to calculate item-total correlations and alpha coefficients to assess the reliability of the scales. Five additional items were removed as they exhibited small item-total correlations, contributing to a low reliability in their scale. In summary, a total of a total of 38 items grouped in five factors were kept representing the competencies of cultural sensitivity, adaptability/ flexibility, global citizenship, resiliency/ hardiness, and global competitor (global vision was eliminated because its items seemed to load on other scales). Overall, the factor analysis concurred with the content validity assessment as most items reflected the competencies for which they were developed.

\section{Participants}

Fifty-seven foreign workers in the Dominican Republic participated in this study. Participants worked across many fields, belonging to approximately 15 different organizations. Participants were from 17 different countries, with approximately $57 \%$ of them being Latin-American, 26\% European, and $17 \%$ were North-American. The average age of participants was 38.44 years. Seventy-five percent were male while fifty-five percent reported having children. Of those 
Table 2. Means, Standard Deviations, Correlations and Reliability of Global Competencies

\begin{tabular}{|c|c|c|c|c|c|c|c|c|}
\hline Scale & $\begin{array}{c}\text { No. } \\
\text { Items }\end{array}$ & M & SD & 1 & 2 & 3 & 4 & 5 \\
\hline 1. Cultural Sensitivity & 7 & 3.40 & .61 & $(.71)$ & & & & \\
\hline 2. Adaptability/Flexibility & 4 & 4.11 & .48 & $.16^{* *}$ & $(.55)$ & & & \\
\hline 3. Global Citizenship & 8 & 3.52 & .41 & $.32 * *$ & $.25 * *$ & $(.71)$ & & \\
\hline 4. Resiliency/Hardiness & 12 & 3.50 & .54 & $.41 * *$ & $.28^{* *}$ & $.22 * *$ & $(.81)$ & \\
\hline 5. Global Competitor & 7 & 3.49 & .57 & $.13^{*}$ & $.22 * *$ & .11 & $.36 * *$ & (.68) \\
\hline
\end{tabular}

who reported having children, $79 \%$ of them had at least one child accompanying them on the assignment. All participants had at least a bachelor's degree and reported holding their current job an average of 2.6 years. About $50 \%$ reported being in their first international assignment.

Because the surveys were distributed through the respective human resource manager, who decided how many surveys to distribute, it was difficult to estimate a response rate. Additionally, seven participants requested not to fill out the demographics portion of the questionnaire. To assure their participation, this request was accommodated.

\section{Procedure}

Organizations were selected because they were known to the authors to employ international assignees. Participants were asked to take the Global Competencies survey, a measure of the Big Five, and a demographics measure. Immediate superiors were asked to fill out a performance measure and a demographic survey. These raters were also located in the Dominican Republic.

\section{Measures}

Big-Five Factors. The measure of the Big Five employed here is available at the International Personality Item Pool website (Goldberg 1999; International Personality Item Pool, 2001). A detailed description can be found in the website http:// ipip.ori.org/ as well as in Goldberg's (1999). Coefficient alphas reported at the website range from .79 to .87 .

Global Competencies Self-assessment. As explained, this instrument was developed in this study to assess the context-specific competencies defined earlier. The sample used in the pilot study (see description of factor analysis above) yielded acceptable alpha coefficients for four of the scales ranging from .68 to
.81. However, the alpha for the adaptability/flexibility scale was fairly low at .55 (see Table 2).

Criterion. Raters were asked to formulate nine ratings of performance on items reflecting interpersonal, technical, and extra role performance (5-point scales were employed). Caliguri (2000) employed a similar performance measure. An overall performance composite was also computed by adding across all nine ratings. This composite had an alpha of .94.

\section{Results}

Correlations and reliabilities are reported in Table 3. As a result of the high correlations among the different performance dimensions (task, contextual, and interpersonal), performance was analyzed only at the overall level, combining all three facets into a composite measure. Among the demographic variables explored as potential controls, only two were found to significantly correlate with performance, namely nationality and having children along. Nationality was not included in subsequent analyses because hiring on the basis of national origin does not conform to the provisions of Title VII of the Civil Rights Act of 1964 (Civil Rights Act of 1964, 42 U.S.C. 200e). Bringing children along on the assignment was dummy-coded where 1 meant bringing at least one offspring and 0 was bringing or having none. This variable had a statistically significant, negative correlation with performance $(r=-.32, p<.01)$.

Hypothesis 1 received partial support. Three of the Global Competencies (i.e., cultural sensitivity, global citizenship, and resiliency/hardiness) were significantly correlated with performance. Conversely, adaptability/flexibility and global competitor were not significantly correlated with performance. To test the second hypothesis, hierarchical regressions were computed. Bringing children along on the assignment was entered at the first step followed by the block of the Big Five Factors at step two. There was no significant F-change upon entering the Big Five. At the third step, the Global Competencies were entered. Unlike in the previous step, a significant $\mathrm{F}$-change $(5,39)=2.41$, 
Table 3. Correlations between Big Five, Global Competencies and Performance

\begin{tabular}{|c|c|c|c|c|c|c|c|c|c|c|c|c|}
\hline Variables & 1 & 2 & 3 & 4 & 5 & 6 & 7 & 8 & 9 & 10 & 11 & 12 \\
\hline \multicolumn{13}{|c|}{ 1. Having child along on assign ${ }^{a}$} \\
\hline 2. Cultural Sensitivity & -.03 & $(.68)^{\mathrm{e}}$ & & & & & & & & & & \\
\hline 3. Adaptability/Flexibility & .04 & .06 & $(.64)^{\mathrm{e}}$ & & & & & & & & & \\
\hline 4. Global Citizenship & -.01 & .04 & .22 & $(.50)^{\mathrm{e}}$ & & & & & & & & \\
\hline 5. Resiliency/ Hardiness & $-.26^{*}$ & $.31 *$ & $.44 * *$ & $.26^{*}$ & $(.80)^{\mathrm{e}}$ & & & & & & & \\
\hline 6. Global Competitor & -.07 & .15 & $.27 *$ & .20 & $.46^{* *}$ & $(.75)^{\mathrm{e}}$ & & & & & & \\
\hline 7. Openness to experience & $-.26^{*}$ & .12 & $.40^{* *}$ & .14 & .22 & $.30^{*}$ & $(.66)^{\mathrm{e}}$ & & & & & \\
\hline 8. Agreeableness & -.17 & $.27 *$ & $.32 *$ & $.29^{*}$ & $.51 * *$ & $.36^{* *}$ & $.42 * *$ & $(.70)^{\mathrm{e}}$ & & & & \\
\hline 9.Conscientiousness & $-.34 *$ & .07 & $.39 * *$ & $.48 * *$ & $.64 * *$ & $.66^{* *}$ & $.30 *$ & $.31 *$ & $(.83)^{\mathrm{e}}$ & & & \\
\hline 10. Neuroticism & $.41 * *$ & -.19 & -.19 & -.12 & $-.63 * *$ & -.24 & -.20 & $-.31 *$ & $-.46 * *$ & $(.85)^{\mathrm{e}}$ & & \\
\hline 11. Extraversion & -.18 & $.37 * *$ & .02 & .23 & $.38 * *$ & $.33^{*}$ & $.33^{*}$ & $.51 * *$ & $.30^{*}$ & -.11 & $(.84)^{\mathrm{e}}$ & \\
\hline 12. Overall performance & $-.32 *$ & $.38 * *$ & .18 & $.26^{*}$ & $.27 *$ & .09 & .23 & $.35^{* *}$ & $.29 *$ & -.16 & .24 & $(.94)^{\mathrm{e}}$ \\
\hline
\end{tabular}

Note. $\mathrm{n}=57$

a Dichotomized where 1 is having a child along during the assignment.

${ }^{\mathrm{e}}$ Correlations in the diagonal represent coefficient alphas computed in this study.

$* p<.05$. ** $p<.01$.

$\left(\Delta \mathrm{R}^{2}=.19 p \leq .05\right)$ emerged upon entering the global competencies (see Table 4).

Because the Big Five Factors and the Global Competencies were somewhat intercorrelated and, therefore, might have suppressed each other's effects, an additional analysis was conducted. That is, the Global Competencies were entered in the second step (before the Big Five and after having children along), followed by the Big Five at step three. In this case, the F-change from entering the Global Competencies at the second step was statistically significant, F-change $(5,44)=3.02,\left(\Delta \mathrm{R}^{2}=.23 p \leq .05\right.$. On the other hand, the
F-change was not significant when the Big Five were entered at the third step (see Table 5). Taken together, these results support hypothesis 2, which stated that the Global Competencies have incremental validity in IAs above and beyond the Big Five.

\section{Discussion}

The present study sought to evaluate the extent to which context-specific competencies predict performance above and beyond broad-based personality fac-

Table 4. Incremental Validity of Global Competencies over Big Five Factors on Overall Performance

\begin{tabular}{|c|c|c|c|c|c|c|}
\hline Step & Predictor & $\begin{array}{c}\mathrm{F} \\
\text { change }\end{array}$ & df & $\mathrm{R}^{2}$ & $\Delta \mathrm{R}^{2}$ & $\beta^{\mathrm{a}}$ \\
\hline 1 & Having child with during assignment & $5.77 *$ & 1,49 & .10 & .10 & $-.32 *$ \\
\hline \multirow[t]{6}{*}{2} & Big Five Scales & 1.12 & 5,44 & .20 & .10 & \\
\hline & Openness & & & & .05 & \\
\hline & Agreeableness & & & & & .25 \\
\hline & Conscientiousness & & & & & .16 \\
\hline & Neuroticism & & & & & .11 \\
\hline & Extraversion & & & & & .01 \\
\hline \multirow[t]{6}{*}{3} & Global Competencies & $2.41 *$ & 5,39 & .39 & .19 & \\
\hline & Cultural Sensitivity & & & & & $.45^{* *}$ \\
\hline & Adaptability/Flexibility & & & & & .04 \\
\hline & Global Citizenship & & & & & .05 \\
\hline & Resiliency/Hardiness & & & & & -.06 \\
\hline & Global competitor & & & & & -.26 \\
\hline
\end{tabular}

Note. ${ }^{a} \beta=$ Standardized regression weight.

$* p<.05$.

$* * p<.01$. 
Table 5. Incremental Validity of Global Competencies over Big Five Factors on Overall Performance (Global Competencies Second Step)

\begin{tabular}{|c|c|c|c|c|c|c|}
\hline Step & Predictor & $\begin{array}{c}\mathrm{F} \\
\text { change }\end{array}$ & df & $\mathrm{R}^{2}$ & $\Delta \mathrm{R}^{2}$ & $\beta^{\mathrm{a}}$ \\
\hline 1 & Having child with during assignment & $5.77 *$ & 1,49 & .10 & .10 & $-.32 *$ \\
\hline \multirow[t]{6}{*}{2} & Global Competencies & $3.02 *$ & 5,44 & .33 & .23 & \\
\hline & Cultural Sensitivity & & & & & $.41 * *$ \\
\hline & Adaptability/Flexibility & & & & & .15 \\
\hline & Global Citizenship & & & & & .18 \\
\hline & Resiliency/Hardiness & & & & & -.03 \\
\hline & Global competitor & & & & & -.07 \\
\hline \multirow[t]{6}{*}{3} & Big Five Scales & .78 & 5,39 & .39 & .06 & \\
\hline & Openness & & & & & .03 \\
\hline & Agreeableness & & & & & .26 \\
\hline & Conscientiousness & & & & & .36 \\
\hline & Neuroticism & & & & & .20 \\
\hline & Extraversion & & & & & -.15 \\
\hline $\begin{array}{l}\text { Note. }{ }^{\text {af }} \\
* p<.0 \\
* * p<.\end{array}$ & andardized regression weight. & & & & & \\
\hline
\end{tabular}

tors. As anticipated, cultural sensitivity, global citizenship and resiliency/hardiness were found to significantly correlate with supervisory ratings of performance. However, adaptability/flexibility and global competitor did not significantly correlate with performance.

The lack of a relationship between adaptability/flexibility and performance has a parallel in the results reported by Caligiuri (2000), where agreeableness was not found to correlate with performance. Indeed, flexibility has been noted to be a facet of agreeableness (Ones \& Viswesvaran, 1997). Thus, similar to agreeable individuals, adaptable or flexible individuals might be viewed as "soft" or wanting to avoid conflict, and thus not necessarily competent. Hence, while being adaptable and flexible might help in other aspects of the assignment such as establishing social relationships or adapting to the new environment, it might hurt superiors' evaluations of expatriate performance.

The lack of a relationship between global competitor and performance can be attributed to cultural differences. In their research using personality as a predictor of overseas performance, Dalton and Wilson (2000) reported that facets of extraversion such as ambition and dominance were perhaps being negatively perceived in some cultures. Similarly, while being competitive and aggressive might be considered positive in one culture, they might be frowned upon in a different one. Anecdotal evidence of overly aggressive American managers abroad also supports this explanation (Sanchez et al., 2000).

Although not predicted by our hypotheses, two demographic variables were significantly correlated with performance. First, being Latin-American was strongly related to performance $(r=.71, p<.01)$. An inspection of the respective means indicated that foreigners from Latin countries were rated higher than their American and European counterparts $(\mathrm{M}=4.60$, $\mathrm{SD}=.34$ vs. $\mathrm{M}=3.56, \mathrm{SD}=.69), \mathrm{t}(51)=7.26, p<.001$. Since almost all of the superiors were Dominicans and therefore Latin-American themselves, perhaps they were more lenient when rating Latin-Americans than when rating others. This finding is consistent with Dalton and Wilson's (2000) results that personality scales correlated significantly with supervisory rated performance only when the ratings were from home country bosses, but not when ratings were from host country bosses. An alternate explanation is that by having a cultural background similar to host nationals, Latin-American expatriates are better equipped to manage in the local environment.

A negative, statistically significant correlation with performance was found between bringing children along and performance. Interestingly, previous studies have reported a relationship between the adjustment of family members and expatriate outcomes such as intent to leave (Alampay, Beehr, \& Christiansen, 2000; Black \& Gregerson, 1991). In our study, bringing children along during the assignment was significantly correlated, albeit negatively, to only one of the global competencies: resiliency/hardiness. This finding suggests that bringing children on the assignment might add to the pressure already faced during an IA, thereby hurting performance.

The second hypothesis was also supported by the 
incremental validity of the Global Competencies above and beyond the Big Five. However, this finding was primarily due to cultural sensitivity. This result is not surprising because some form of cultural sensitivity (i.e. respect for differences, non-judgmentalness) has been suggested to be sine qua non of successful expatriates. Perhaps most importantly, our results showed that context-specific predictors might indeed be better predictors of performance during IAs than non-specific, broad predictors.

Form a theoretical viewpoint, our data hint that specific, context-relevant predictors can enhance our understanding of the impact personality can have on IAs. Consider for instance that, consistent with Caligiuri's (2000) study, extraversion was not found to correlate significantly with supervisory ratings of performance. An inspection of Table 3, however, reveals a statistically significant, positive correlation between extraversion and both cultural sensitivity and resilience/hardiness. Moreover, cultural sensitivity and resilience/ hardiness were correlated with overall performance in our study. In other words, although extraversion did not show a significant correlation with performance, it shows a correlation with context-specific global competencies that were in turn correlated with performance. This finding suggests that even though overall extraversion might not be a good predictor of performance during IAs, certain facets of extraversion, such as showing persistence in trying to understand and communicate with others (as opposed to being overly assertive) might indeed predict performance. This insight illustrates how using broad scales might mask important nuances in the relationship between personality and performance in IAs.

There were several limitations in this study. First, the sample came from only one country, therefore restricting the generalizability of our findings. Likewise, while the scales were not designed with a specific culture in mind, it is quite possible that the Global Competencies used in this study might not be equally valid predictors of performance for individuals working in other, culturally different environments. Future research should obtain larger and more diverse sample from a greater number of countries to uncover the boundaries of the findings reported here.

In summary, given the taxing interpersonal requirements of IAs, it seems reasonable to use personality measures to supplement other selection tools such as those tapping technical knowledge and other knowledge, skills, and abilities based on job analysis. However, our data hint that practitioners may be better off preferring personality-related competencies that incorporate the context of IAs over Big Five measures. Because of the relatively low cost involved in administering short scales like the ones employed here, multinational corporations may benefit from adding context-specific assessments to their international selection systems.

\section{References}

Alampay, R. H., Beehr, T. A., \& Christiansen, N. D., (2000, March). Antecedents and consequences of employees' adjustment to overseas assignments. Poster session presented at the annual meeting of the Society for Industrial and Organizational Psychology, New Orleans, LA.

Arthur, W., Jr., \& Bennett, W., Jr. (1995). The international assignee: The relative importance of factors perceived to contribute to success. Personnel Psychology, 48, 99-114.

Ashton, M. C. (1998). Personality and job performance: the importance of narrow traits. Journal of Organizational Behavior, 19, 289-303.

Aycan, Z. (2001). Expatriation: A critical step toward developing global leaders. In Mendenhall, M. E., Kühlmann, T. M., \& Stahl, G. K. (Eds.), Developing global business leaders: Policies, processes, and innovations (pp. 119135). Westport, CT: Greenwood.

Barrick, M. R., \& Mount, M. K. (1991). The big five personality dimensions and job performance: A meta-analysis. Personnel Psychology, 44, 1-26.

Black, J. S., \& Gregersen, H.B. (1991). The other half of the picture: Antecedents of spouse cross-cultural adjustment. Journal of International Business Studies, 22, 461-477.

Black, J. S., \& Gregersen, H. B. (1999). The right way to manage expats. Harvard Business Review, 77, 52-62.

Black, J. S., Gregersen, H. B., Mendenhall, M. E., \& Stroh, L. K. (1999). Globalizing people through international assignments. Reading, MA: Addison-Wesley.

Black, J. S., Mendenhall, M. E., \& Oddou, G. (1991). Toward a comprehensive model of international adjustment: An integration of multiple theoretical perspectives. Academy of Management Review, 16, 291-317.

Black, J. S., Morrison, A. J., \& Gregersen, H. B. (1999). Global explorers: The next generation of leaders. New York: Routledge.

Caligiuri, P. M. (2000). The big five personality characteristics as predictors of expatriate's desire to terminate the assignment and supervisor-rated performance. Personnel Psychology, 53, 67-88.

Church, A. T. (1982). Sojourner adjustment. Psychological Bulletin, 91, 540-572.

Dalton, M., \& Wilson, M. (2000). The relationship of the five-factor model of personality to job performance for a group of Middle Eastern expatriate managers. Journal of Cross-Cultural Psychology, 31, 250-258.

Deller, J. (1997). Expatriate Selection: Possibilities and limitations of using personality scales. In D. M. Saunders (Series Ed.) \& Z. Aycan (Vol. Ed.), New approaches to employee management: Vol. 4. Expatriate Management: Theory and research (pp. 93-116). Greenwich, CT: JAI.

Digman, J. M. (1990). Personality structure: The emergence of the five-factor model. Annual Review of Psychology, 41, 417-440.

Earley, P. C. (1987). Intercultural training for managers: A comparison of documentary and interpersonal methods. Academy of Management Journal, 30, 685-698.

Goldberg, L. R. (1999). A broad-bandwidth, public domain, 
personality inventory measuring the lower-level facets of several five-factor models. In I. Mervielde, I. Deary, F. De Fruyt, \& F. Ostendorf (Eds.), Personality Psychology in Europe, Vol. 7 (pp. 7-28). Tilburg, The Netherlands: Tilburg University Press. Obtained through website http://ipip.ori.org/ipip/.

Goldsmith, K., \& Walt, C. (2000). New competencies for tomorrow's global leader. CMA Management, 73, 20-24.

Gregersen, H. B., Morrison, A. J., \& Black, J. S. (1998). Developing leaders for the global frontier. Sloan Management Review, 40, 21-32.

Hitt, M. A., Keats, B. W., \& DeMarie, S. M. (1998). Navigating in the new competitive landscape: Building strategic flexibility and competitive advantage in the $21^{\text {st }}$ century. The Academy of Management Executive, 12, 2242.

Hogan, G. W., \& Goodson, J. R. (1990). The key to expatriates success. Training and Development Journal, 44, 50-52.

Hogan, J., \& Roberts, B. W. (1996). Issues and non-issues in the fidelity-bandwidth trade-off. Journal of Organizational Behavior, 17, 627-637.

Hough, L. M., Eaton, N. K., Dunnette, M. D., Kamp, J. D., \& McCloy, R. A. (1990). Criterion-related validities of personality constructs and the effect of response distortion on those validities. Journal of Applied Psychology, 75, 581-595.

International Personality Item Pool (2001). A Scientific Collaboratory for the Development of Advanced Measures of Personality Traits and Other Individual Differences (http://ipip.ori.org/). Internet Web Site.

Lipp, D. G., \& Clarke, C. H. (2000). Managing culture. Executive Excellence, 17(12), 12-14.

Marquardt, M. J., \& Berger, N. O. (2000). Global leaders for the $21^{\text {st }}$ century. New York: State University of New York.

Marquardt, M. J., Engel, \& D. W. (1993). Global human resource development. Engelwood Cliffs, NJ: Prentice Hall.

McCall, M. W., Jr. (1994). Identifying leadership potential in future international executives: Developing a concept. Consulting Psychology Journal, 46, 49-63.

McCrae, R. R., \& Costa, P. T. (1987). Validation of the FiveFactor Model of Personality Across Instruments and Observers. Journal of Personality and Social Psychology 52, 81-90.

Mendenhall, M. E. (2001). Introduction: New perspectives on expatriate adjustment and its relationship to global leadership development. In Mendenhall, M. E., Kühlmann, T. M., \& Stahl, G. K. (Eds.), Developing global business leaders: Policies, processes, and innovations (pp. 1-16). Westport, CT: Greenwood.

Mendenhall, M. E., \& Oddou, G. (1985). The dimensions of expatriate acculturation. Academy of Management Review, 10, 39-47.

Oddou, G., Gregersen, H. B., Black, J. S., \& Derr, C. B. (2001). Building global leaders: Strategy similarities and differences among European, U.S., and Japanese multinationals. In Mendenhall, M. E., Kühlmann, T. M., \& Stahl, G. K. (Eds.), Developing global business leaders: Policies, processes, and innovations (pp. 99-116). Westport, CT: Greenwood.

Odenwald, S. (1996). Global work teams. Training \& Development, 50, 54-58.

Ones, D. S., \& Viswesvaran, C. (1996). Bandwidth-fidelity dilemma in personality measurement for personnel selection. Journal of Organizational Behavior, 17, 609-626.

Ones, D. S., \& Viswesvaran, C. (1997). Personality determinants in the prediction of aspects of expatriate job success. In D. M. Saunders (Series Ed.) \& Z. Aycan (Vol. Ed.), New approaches to employee management: Vol. 4. Expatriate management: Theory and research (pp. 6392). Greenwich, CT: JAI.

Sanchez, J. I., Spector, P. E., \& Cooper, C. L. (2000). Adapting to a boundaryless world: A developmental expatriate model. Academy of Management Executive, 14, 96-106.

Saner, R., Yiu, L., \& Sondergaard, M. (2000). Business diplomacy management: A core competency for global companies. Academy of Management Executive, 14, 8092.

Schneider, R. J., Hough, L. M., \& Dunnette, M. (1996). Broadsided by broad traits: How to sink science in five dimensions or less. Journal of Organizational Behavior, 17, 639-655.

Spreitzer, G. M., McCall, M. W., Jr., \& Mahoney, J. D. (1997). Early identification of international executive potential. Journal of Applied Psychology, 82, 6-29.

Stahl, G. K. (2001). Using assessment centers as tools for global leadership development. In Mendenhall, M. E., Kühlmann, T. M., \& Stahl, G. K. (Eds.), Developing global business leaders: Policies, processes, and innovations (pp. 197-210). Westport, CT: Greenwood.

Title VII of the Civil Rights Act of 1964, 42 U.S.C. 2000e.

Manuscript Received: 06/11/2010

Revision Received: 20/01/2011

Accepted: 20/01/2011 